\title{
Postgraduate Course
} ERS Copenhagen 2005 The side-effects of TB therapy

\section{Educational aims}

R. Zaleskis

WHO Regional Office for Europe Regional Advisor, Tuberculosis Control WHO Regional Office for Europe 8 Scherfigsvej DK 2100 Copenhagen Denmark

Fax: 4539171851

E-mail: rza@who.dk

To provide up-to-date insights on:

I the side-effects of anti-TB chemotherapy

the symptom-based approach to the management of side-effects

I the influence of side-effects on the outcomes of anti-TB treatment.

\section{Summary}

There is still much debate concerning the frequency and severity of symptoms of TB when undergoing chemotherapy. In addition, the frequency of complications is hard to quantify as many patients are treated with a range of different drugs. However, this article aims to give a brief overview of the side-effects associated with anti-TB drugs and the most appropriate management approaches to take.

It has been suggested that only a minority of patients successfully complete their full course of anti-tuberculosis (TB) chemotherapy without significant side-effects. There is also an opposing view that most patients with TB complete their treatment without serious adverse effects. What is the truth? Modern anti-TB chemotherapy regimens have been in use for $>30$ years. However, the frequency of severe complications is not well known, probably due to lack of notification and under-reporting. It is clear that many patients have adverse reactions which complicate treatment and have an influence on treatment outcomes. However, it is difficult to measure the efficacy or toxicity of a particular drug, since anti-TB drugs are usually administered in combination regimens of several drugs. Therefore, any care provider treating a TB patient is assuming a public health function that includes not only prescribing an appropriate regimen, but also ensuring adherence to the regimen and monitoring of the treatment, including the side-effects of drugs until treatment is completed.

\begin{tabular}{|ll|}
\hline Glossary \\
Amk: & Amikacin \\
$\mathrm{Cm}:$ & Capreomicin \\
$\mathrm{Cs}:$ & Cycloserine \\
$\mathrm{E}:$ & Ethambutol \\
$\mathrm{H}:$ & Isoniazid \\
$\mathrm{Et}:$ & Ethionamide (Prothionamide) \\
$\mathrm{Km}:$ & Kanamycin \\
$\mathrm{O}:$ & Ofloxacin \\
Pas: & Para-aminosalicylic acid \\
$\mathrm{R}:$ & Rifampicin \\
$\mathrm{S}:$ & Streptomycin \\
Tha: & Thioacetazon \\
$\mathrm{Z:}$ & Pyrazinamide \\
\hline
\end{tabular}




\section{Table $1 \quad$ Adverse effects of essential anti-TB drugs}

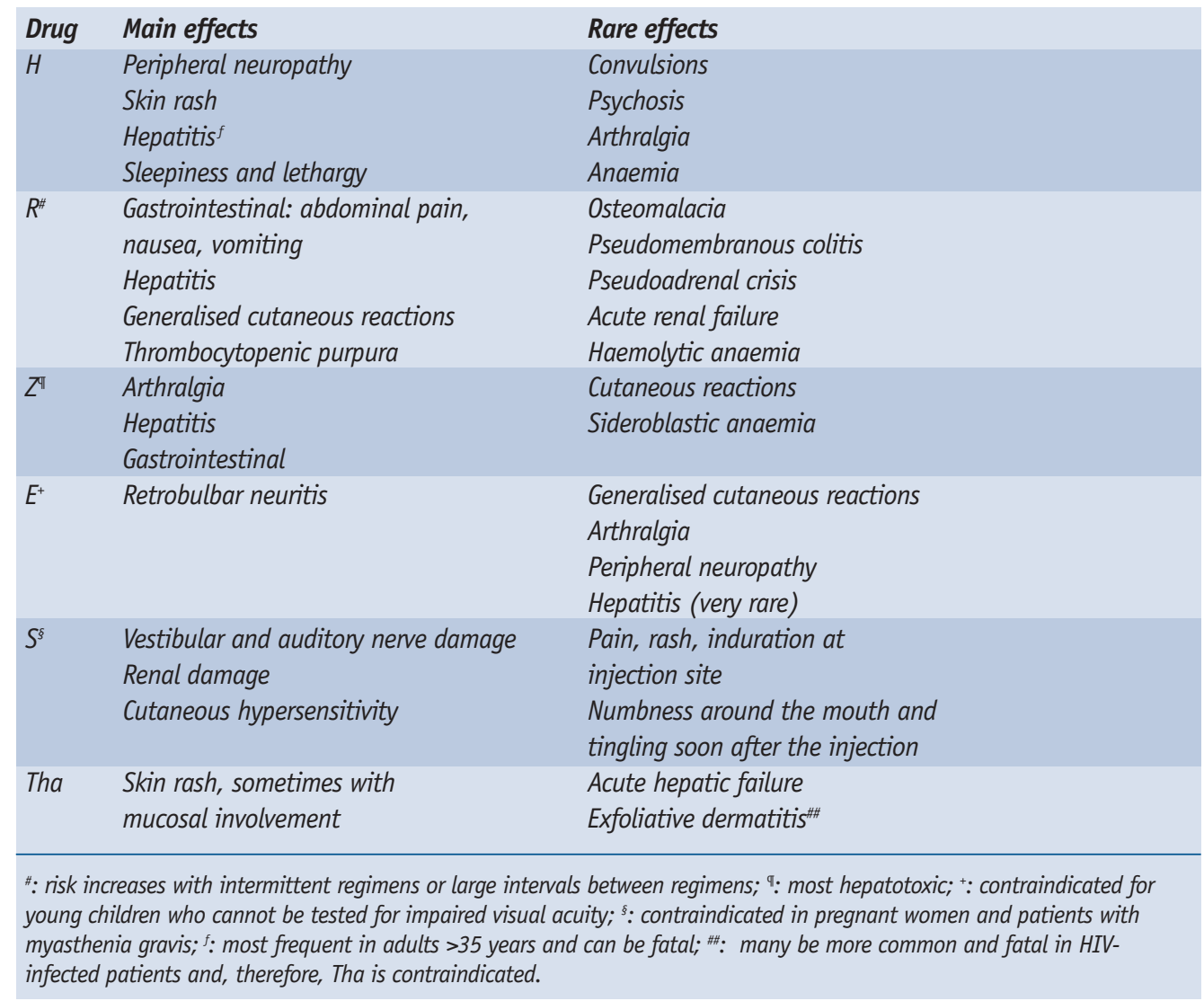

\section{Table 2 Adverse effects of reserve anti-TB drugs}

\begin{tabular}{|c|c|c|}
\hline Drug & Main effects & Rare effects \\
\hline$K m^{\#}$ & Vestibular (vertigo) and auditory & Cutaneous hypersensitivity \\
\hline$A m^{\#}$ & nerve damage & Clinical renal failure \\
\hline $\mathrm{Cm}^{\#}$ & Nephrotoxicity & \\
\hline$E t^{*}$ & $\begin{array}{l}\text { Gastrointestinal: anorexia, nausea, } \\
\text { diarrhoea, abdominal pain } \\
\text { Hepatotoxicity }\end{array}$ & $\begin{array}{l}\text { Convulsion } \\
\text { Mental symptoms } \\
\text { Impotence } \\
\text { Gynaecomastia }\end{array}$ \\
\hline Fluoroquinolones ${ }^{\sharp, q}$ & $\begin{array}{l}\text { Gastrointestinal: anorexia, } \\
\text { nausea, vomiting }\end{array}$ & $\begin{array}{l}\text { Anxiety } \\
\text { Dizziness } \\
\text { Headache } \\
\text { Convulsion } \\
\text { Rupture of the Achilles tendon }\end{array}$ \\
\hline $\mathrm{CS}^{+}$ & $\begin{array}{l}\text { Dizziness } \\
\text { Headache } \\
\text { Depression } \\
\text { Psychosis } \\
\text { Convulsion }\end{array}$ & $\begin{array}{l}\text { Suicide } \\
\text { Generalised hypersensitivity } \\
\text { Hepatitis }\end{array}$ \\
\hline $\mathrm{Pas}^{+}$ & $\begin{array}{l}\text { Gastrointestinal: anorexia, nausea, } \\
\text { vomiting } \\
\text { Hypersensitivity reactions } \\
\text { (fever, rash, pruritus) }\end{array}$ & $\begin{array}{l}\text { Hypothyroidism } \\
\text { Haematological reactions }\end{array}$ \\
\hline
\end{tabular}




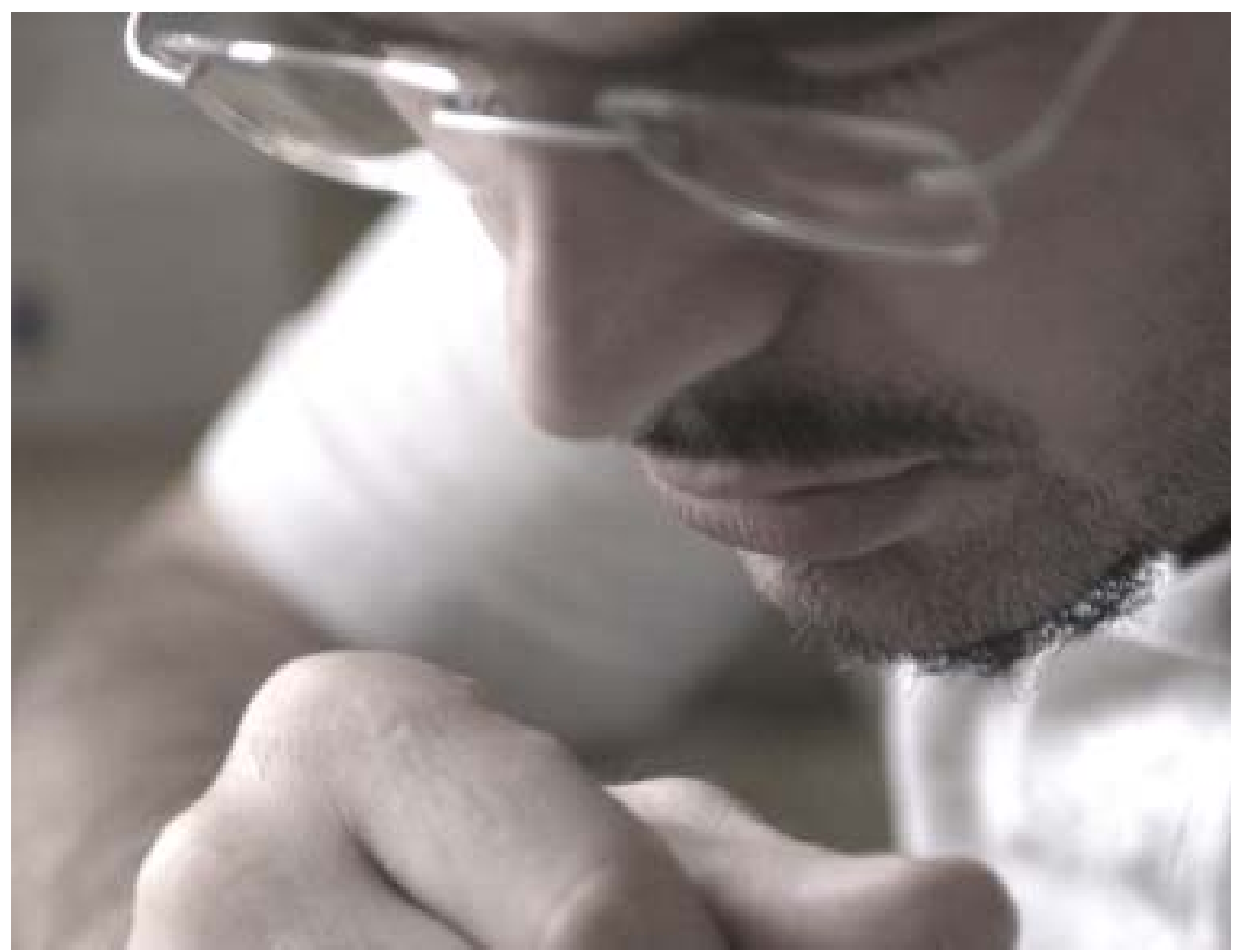

\section{Adverse effects of anti-TB drugs}

Essential anti-TB drugs are those used in as firstline therapy. The adverse effects of essential anti-TB drugs are given in table 1.

Reserve anti-TB drugs are those used in 2ndline (drug-resistant TB) treatment. The adverse effects of reserve anti-TB drugs are given in table 2.

\section{What to do if symptoms of adverse effects occur}

If symptoms of adverse effects occur the following should be done:

$>$ the dose of drugs should be checked

$>$ all other causes of symptoms should be excluded

$>$ the seriousness of the adverse effects should be estimated

$>$ the adverse effects should be registered

$>$ the drugs should eventually be reintroduced gradually when symptoms disappear

$>$ the development of drug resistance should be avoided.

\section{Symptom-based approach to the management of adverse effects}

The following tables give a brief description of how adverse effects should be managed when the effect are minor (table 3) and major (table 4).

\section{Management of hepatotoxicity}

Hepatotoxicity is the most common cause of iatrogenic disease in TB treatment. Anti-TB drugs can induce various degrees of hepatotoxicity, from a transitory asymptomatic rise in transaminases (which in extreme cases may lead to interruption of TB treatment), to acute liver failure (ALF) (when hepatic encephalopathy occurs and prothrombine time is $<50 \%$, usually leading to the need for liver transplantation or even death). The frequency of hepatotoxicity in different countries varies $1-10 \%$.

Hepatotoxicity due to isoniazid is most common, as isoniazid has been used for TB treatment (both latent and active TB) since 1952. However, pyrazinamide is the most hepatotoxic among essential anti-TB drugs, in particular at doses of $>30 \mathrm{mg}$ per $\mathrm{kg}$ per day. Rifampicin has a low hepatotoxicity. However, due to its enzyme-

Table 3 Symptom-based approach to the management of minor adverse effects: continue anti-TB drugs

\begin{tabular}{|lll|}
\hline Adverse effects & Drug & Management \\
Anorexia, nausea, abdominal pain & $R, Z, E t, 0$, Pas & Small meals or last thing at night \\
Arthralgia & $Z,(H, E), 0$ & Aspirin \\
Burning in the feet & $H$ & Pyridoxine $100 \mathrm{mg}$ \\
Orange/red urine & $R$ & Reassurance (explanation) \\
\hline
\end{tabular}


Table 4 Symptom-based approach to the management of major adverse effects: stop anti-TB drugs

$\begin{array}{lll}\begin{array}{l}\text { Adverse effects } \\ \text { Deafness (no wax on auroscopy) }\end{array} & \text { Drug } & \text { Management } \\ \text { Dizziness } & S, K m, A m k, C m & \text { Use } E \\ \begin{array}{l}\text { Jaundice hepatitis } \\ \text { (other causes excluded) }\end{array} & \begin{array}{l}H, Z, R, T h a, E, E t, \\ \text { CS, Pas }\end{array} & \begin{array}{l}\text { Use } E \\ \text { Re-introduce drugs grouped } \\ \text { serially while monitoring liver } \\ \text { function, with most likely agent } \\ \text { introduced last }\end{array} \\ \begin{array}{lll}\text { Itching, skin rash } \\ \text { Vomiting/confusion }\end{array} & \begin{array}{l}\text { Tha, S, H, R, Z, Pas } \\ \text { Antihistamines, steroids }\end{array} \\ \begin{array}{l}\text { Visual impairment } \\ \text { (other causes excluded) }\end{array} & \text { hepatitis } & \begin{array}{l}\text { Urgent liver function tests and } \\ \text { prothrombin time }\end{array} \\ \begin{array}{l}\text { Shock, purpura, acute renal } \\ \text { failure }\end{array} & R, S, K m, A m k & \begin{array}{l}\text { Visual examination } \\ \text { Use different combinations of } \\ \text { drugs }\end{array}\end{array}$

inducer effect it may increase the toxicity of isoniazid when the two drugs are combined.

Mild hepatotoxicity (a rise in transaminases of 3-5 times the normal level) does not require any modification in treatment, only more frequent visits and laboratory tests. In cases of moderate hepatotoxicity (a rise in transaminases of between 3-5 and 10 times the normal level), chemotherapy should be stopped as soon as possible, controlling for the risk of ALF should be started and patients should be hospitalised if necessary. However, the risk of ALF is low.

Severe hepatotoxicity (a rise in transaminases $>10$ times the normal level) occurs in one out of every 1,000 cases treated, and is associated with a high fatality rate of $\sim 2.5 \%$. Hepatitis is the usual clinical manifestation at this degree of toxicity and the risk of ALF is high. Spontaneous

\begin{tabular}{|c|c|c|}
\hline$T a b$ & $\begin{array}{l}\text { Man } \\
\text { rein } \\
\text { drug }\end{array}$ & $\begin{array}{l}\text { ement of severe rash: } \\
\text { duction of anti-TB }\end{array}$ \\
\hline Day & Drug & Dose \\
\hline 1 & $H$ & $50 \mathrm{mg}$ \\
\hline 2 & $H$ & $300 \mathrm{mg}$ \\
\hline 3 & $R H$ & 1/2 tablet \\
\hline 4 & $R H$ & 1 tablet \\
\hline 5 & $R H$ & Full dose \\
\hline 6 & $R H+Z$ & Day 5 dose $+1 / 2$ tablet \\
\hline 7 & $R H+Z$ & Day 5 dose +1 tablet \\
\hline 8 & $R H+Z$ & Full dose \\
\hline 9 & $R H+Z+E$ & Day 8 dose $+1 / 2$ tablet \\
\hline 10 & $R H+Z+E$ & Day 8 dose +1 tablet \\
\hline 11 & $R H+Z+E$ & Full dose \\
\hline 12 & $R H+Z+E$ & Full dose \\
\hline
\end{tabular}

survival after ALF is $<10 \%$. The only treatment that increases survival is liver transplantation (survival rates $>80 \%$ ).

\section{Management of severe rash: reintroduction of anti-TB drugs}

Itching/skin rash is also a very common major adverse effect of anti-TB chemotherapy, which requires a quick response. Table 5 provides a guide to how a patient should be managed in this situation.

\section{Life-threatening adverse effects}

Life-threatening adverse effects include anaphylaxis, severe toxic, allergic reactions (exfoliative dermatitis, syndrome Steewen-Johnson), severe gastritis with bleeding, severe hepatitis and renal failure. In such circumstances, treatment must be stopped. If the offending drug is unknown then all drugs must be continued and the emergency department contacted.

\section{The influence of side-effects on the outcomes of anti-TB treatment}

One concern when considering side-effects is whether they prevent patients from taking medication and, hence, influence the outcomes of anti-TB treatment. In the cohort year of 2002 , the global success rate of treatment with standardised anti-TB chemotherapy with 1st-line drugs was $82 \%$ and the WHO European region success rate was $76 \%$ [1]. In the results from five DOTSplus projects (Estonia, Latvia, Orel, Philippines and Tomsk), only $2 \%$ of 924 patients stopped treatment, although 30\% did require removal of the suspected drug from the regime due to adverse effects. The five most-common reported effects included: nausea/vomiting (32.8\%), diarrhoea $(21.1 \%)$, arthralgia (16.4\%), dizziness/vertigo (14.3\%) and hearing disturbances $(12.0 \%)$ [2]. Hence, side-effects of anti-TB chemotherapy need not necessarily adversely effect outcomes.

\section{Conclusions}

In conclusion, the main adverse effects of anti-TB drugs usually occur during the first $2-3$ weeks of treatment. If these side-effects are not recognised on time and managed properly they can lead to treatment interruption or can even can be life threatening. Proper monitoring has to be carried out during the whole treatment course, including patient education, clinical examination, laboratory tests, etc. 
Adverse effects are manageable in TB treatment provided that appropriate management approaches are applied, including altering dosages when appropriate, ancillary drugs to treat adverse events, discontinuation of drugs if needed, special training for staff on adverse events and standard protocols for registration. A patient-centred, individualised approach to treatment support is a core element of all TB control efforts.

\section{Educational questions}

Which of the following statements are correct?

1. Anti-TB drugs have the following side-effects

a) All. b) None. c) Few. d) Many.

2. This drug is contraindicated in young children:

a) Isoniazid. b) Pyrazinamide. c) Ethambutol. d) Ofloxacin.

3. This drug is contraindicated in pregnant women:

a) Streptomycin. b) Cycloserin. c) Ethionamide. d) Rifampicin.

4. This drug is contraindicated for HIV/AIDS patients:

a) Rifampicin. b) Thioacetazon. c) Ethionamide. d) Pas.

5. Minor adverse effects include:

a) Deafness. b) Anorexia and other gastrointestinal symptoms. c) Jaundice. d) Neither a, b or c.

6. Major adverse effects include:

a) Arthralgia. b) Orange/red urine. c) Nausea. d) Dizziness.

7. Severe hepatotoxicity occurs if there is a rise in transaminases:

a) $>10$ times the normal level. b) $3-5$ times the normal level.

c) From 3-5 to 10 times the normal level. d) Does not depend on the rise in transaminases.

8. Severe hepatotoxicity is associated with:

a) Low mortality rate. b) High mortality rate. c) Acute liver failure. d) Neither $a$, b or c.

9. Life-threatening adverse effects include:

a) Abdominal pain. b) Burning in the feet. c) Exfoliative dermatitis. d) Renal failure.

10. Most of adverse effects of anti-TB drugs are:

a) Manageable. b) Irreversible. c) Life threatening. d) Incurable.

11. Adverse effects of anti-TB drugs can be life threatening:

a) Never. b) If they are not managed properly. c) During the first 2-3 weeks. d) If caused by reserved drugs.

\section{Suggested further reading}

World Health Organization. Treatment of Tuberculosis. Guidelines for National Programmes. 3rd Edn. Geneva, Switzerland, World Health Organization, WHO /CDS/TB/2003.313; pp. 57-60, 87-104.

World Health Organization. Toman's Tuberculosis: Case Detection, Treatment, and Monitoring - questions and answers. 2nd Edn. Geneva, Switzerland, World Health Organization, WHO /HTM/TB/2004.334; pp. 110-121,

152-161.

Enarson DA, Rieder HL, Arnadottir T, Trebucq A. Management of Tuberculosis. A Guide for Low Income Countries. 5th Edn. Paris, International Union Against Tuberculosis and Lung Disease, 2000; pp. 19-21.

World Health Organization: Guidelines for Establishing DOTS-Plus Pilot Projects for the Management of MultidrugResistant Tuberculosis (MDR-TB). Geneva, Switzerland, World Health Organization, WHO /CDS/TB/2000.279; pp. 49-52, 54-65, 68-70, 73, 75-83.

World Health Organization. TB/HIV. A Clinical Manual. 2nd Edn. Geneva, Switzerland, World Health Organization, WHO /HTM/TB/2004.329; pp. 129-136.

Clinical Tuberculosis. 3rd ed. Davies PD0, ed. London, Arnold, 2003; pp. 200-202.

Crofton J, Horne N, Miller F. Clinical Tuberculosis. 2nd ed. MacMilan Press Limited, London, 1999; pp. 172-174, 186-188.

Leimane V, Riekstina $V$, Holtz $T$, et al. Clinical outcome of individualized treatment of multidrug-resistant tuberculosis in Latvia: a retrospective cohort study. Lancet 2005; 365: 318-326.

Tost JR, Vidal R, Cayla J, et al. Severe hepatotoxicity due to anti-tuberculosis drugs in Spain. Int J Tuberc Lung Dis 2005; 9: 534-540.

American Thoracic Society/Centers for Disease Control and Prevention/Infectious Diseases Society of America. Treatment of tuberculosis. Am J Respir Crit Care Med 2003; 167: 603-662.

Girling DJ. Adverse effects of tuberculosis drugs. Drugs 1982; 23: 56-74.

References

1. World Health Organization Report 2005. Global Tuberculosis Control. Geneva, Switzerland, World Health Organization, WHO/HTM/TB/2005.349.

2. Stop TB Working Group on DOTS-Plus for MDR-TB. Paris, France, WHO, 2003.

\section{Suggested answers \\ 1. a \\ 2. c \\ 3. $a$ and $c$ \\ 4. $b$ \\ 5. b \\ 6. d \\ 7. a \\ 8. $b$ and $c$ \\ 9. $c$ and $d$ \\ 10. a \\ 11. b}

